\title{
A ABORDAGEM DE RAÇA/ETNIA E GÊNERO NOS ESPAÇOS EDUCATIVOS: COMUNIDADES ÍNDIGENAS E QUILOMBOLAS, E AS REPRESENTAÇÕES NO ESPAÇO FORMAL DE EDUCAÇÃO
}

\author{
Cassiano Teixeira Rocha ${ }^{1}$ \\ Agda Antunes Balduino ${ }^{2}$ \\ Lisiane Costa Costa ${ }^{3}$ \\ Vilmar Alves Pereira ${ }^{4}$
}

\begin{abstract}
RESUMO: Nosso estudo tem como principal foco a representação de raçaletnia e gênero dentro dos ambientes de ensino, principalmente nos livros das escolas de ensino básico, o qual possui grande relevância na constituição do sujeito. Desse modo a pesquisa fundamentou-se em artigos e em materiais de uma pesquisa em andamento. Busca-se dessa forma demonstrar o quanto é necessário modificar nossas práticas para contribuir numa realidade ainda muito desigual e injusta com relação às camadas populares e comunidades tradicionais. É comentado também acerca de nossos contextos e de nossas contribuições nos mesmos, assim como a importância desses contextos para a transformação dessas realidades. Compreende-se, então, por meio das argumentações dispostas ao longo do artigo, e, da problematização de reproduções conservadoras excludentes da diversidade, ou que tratam o assunto de forma preconceituosa, a necessidade das cotas como meio de ingresso ao ensino superior. Não como resolução dos anos de prejuízos causados aos negros, mas como uma pequena forma de devolver o que lhes foi tirado, bem como a reflexão sobre as opressões que ocorrem não só pela questão racial, mas também pela de desigualdade de gênero ou então da união delas que é grande responsável pela visão denegrida e estereotipada da mulher e pela discriminação que ocorre dia pós dia em todo o canto do Brasil.
\end{abstract}

PALAVRAS-CHAVE: RAÇA/ETNIA. GÊNERO. EDUCAÇÃO POPULAR. PRÉUNIVERSITÁRIO. COMUNIDADE INDÍGENA QUILOMBOLA.

\section{OS CONTEXTOS}

A pesquisa e desenvolvimento das atividades ocorrem baseados na experiência que tivemos desde o início de 2014, em dois contextos, são eles o pré-universitário Acreditar na Escola Tellechea no Parque Marinha, criado em 2004 e que desde 2007

\footnotetext{
1 Graduando de Letras Bacharelado Português/Francês, cassianoteixeirarocha@outlook.com, FURG/Carreiros, PET Conexões de Saberes da Educação Popular e Saberes Acadêmicos, FNDE

2 Graduanda de Artes Visuais Bacharelado, agda.balduino@bol.com.br, FURG/Carreiros, PET Conexões de

Saberes da Educação Popular e Saberes Acadêmicos, FNDE

${ }^{3}$ Doutoranda em Educação Ambiental no PPGEA, lisianecostaclaro@hotmail.com, PET Conexões de Saberes da Educação Popular e Saberes Acadêmicos

4 Doutor em Educação, vilmar1972@gmail.com, PET Conexões de Saberes da Educação Popular e Saberes Acadêmicos.
} 
conta com o apoio do Programa de Auxilio ao Ingresso nos Ensinos Técnico e Superior (PAIETS), onde são realizados encontros educativos em duas turmas Pré-IFRS e PréEnem visando o acesso e a permanência das comunidades populares nesses espaços, com o auxilio da petiana de Artes Visuais. No PAIETS Indígenas e Quilombolas na Furg, com o petiano de Letras, busca-se o reconhecimento, tolerância e acolhida das diferenças numa universidade que se concebe como plural. Ambos os contextos vão além do simples ensinar, mas acreditam numa educação emancipadora e sensibilizadora.

\section{INTRODUÇÃO}

É de suma importância que as questões étnicas e de gênero, que por muitas vezes são veladas e pouco discutidas, principalmente no ambiente escolar, sejam trabalhados nesses contextos, tendo em vista que são ainda muito retrógradas, pois o sentimento de pertencimento do educando a historia da sociedade faz parte dessa construção humana e crítica. Dessa forma torna-se essencial nossa participação nesses espaços, pois dentro destas instituições educacionais é que se formarão novos cidadãos pensantes e que irão tirar como base de convivência social, o ensino construído a partir de seus materiais didáticos e de seus educadores.

A escola é um dos primeiros contatos sociais que temos quando criança, formamos nossas opiniões e, também, nossos preconceitos. Temos de lidar com o termo preconceito como algo existente, cortando a ideia de que vivemos em uma sociedade mais flexível e que aceita mais a diversidade. De fato, nos dias de hoje, estamos em um processo de flexibilidade e aceitação da diversidade, porém ainda presenciamos muitas reproduções preconceituosas, tanto verbais como físicas. Vivemos em uma sociedade onde a mulher, a(o) pobre, a(o) negra(o), homossexual, transexual, têm uma participação na universidade e nos direitos humanos, em termos de quantidade, inferior as classes dominantes.

A desconstrução de tais atos (verbais e físicos) só é possível a partir de uma boa orientação, através da educação de nossos jovens e adultos. É apoiando essa diversidade que o grupo PET Conexões de Saberes da Educação popular e Saberes Acadêmicos têm seus pré-universitários instalados em áreas exclusas pelo capital, que ainda sustenta uma universidade heteronormativa com grandes reproduções conservadoras. Nas comunidades quilombolas da região, nas comunidades urbanas menos favorecidas pelo estado, em resumo, nas camadas populares da nossa cidade, efetivamos um trabalho de inclusão e permanência dos componentes destas camadas na universidade. 


\section{O PRECONCEITO ÉTNICO-RACIAL ACERCA DOS LIVROS DIDÁTICOS E DA LÍNGUA}

De acordo com o dicionário Aurélio, racismo é "doutrina que sustenta a superioridade de certas raças". Partindo desta definição, iremos mostrar argumentos que comprovam a prática de tal ato, pelo ser humano branco no ser humano negro. $\mathrm{O}$ preconceito dentro das instituições de ensino já é perceptível na forma com que os livros didáticos relatam a diversidade. Prova disto é o próprio negro não ter uma representação significativa nos livros de história, a não ser relatado como escravo, o que já está errado, pois o negro não é uma espécie denominada escrava, nascida para obedecer e se submeter, ele foi um ser humano escravizado pela sua mesma espécie que insistia em se diferenciar em uma hierarquia preconceituosa. E quando apontamos este tópico, não estamos querendo esquecer a escravidão, pelo contrário, queremos enfatizar que o negro nunca foi escravo, mas sim escravizado pelo branco. É importante a desconstrução da imagem "salvadora e piedosa" da Princesa Isabel, representando a abolição como um ato de compaixão para com seus escravos. Quando, na verdade, por um interesse econômico, o Brasil foi pressionado pela Inglaterra, uma das grandes potências na época, a libertar os escravizados. Tornando assim o tráfico negreiro ilegal. Somado a isto, criaram-se leis, como a lei do ventre livre e a lei do sexagenário, as quais impossibilitaram a classificação de novos negros escravizados, tornando assim a mão de obra escrava mais cara que a mão de obra livre. Com isso, temos o primeiro indício que história apresentada pelos livros didáticos é um tanto enfeitada. Trata os fatos de uma forma mascarada pela romantização, -palavra que usaria para denominar quando romantizamos algo- que o branco impusera em seus relatos, sempre colocando o ser humano branco como herói. Outro fato são as gravuras, geralmente em livros de ensino fundamental, onde podemos ver as gravuras sempre com uma quantidade superior de personagens, ilustrativo e interativo, brancos em relação aos personagens negros.

Isso já faz com que uma criança negra se sinta pouco representada, ou talvez se sinta como minoria, o que também seria algo fictício. Sabemos bem que a miscigenação entre etnias é bem presente no Brasil. Notamos esta mistura ao nosso redor a todo o momento, como visto no livro de 1953, Complexo de Zé Carioca, de Romero, "Formamos um país mestiço (...) somos mestiços, se não no sangue ao menos na alma".

No Rio Grande do Sul, nos livros didáticos mais tradicionais, e até em 
reproduções de professores mais conservadores, consta que a grande maioria da população é descendente de europeus, e que a maior influência na nossa colonização foi deles. Quando, na verdade, de acordo com a história relatada por comunidades remanescentes de quilombolas e por muitos escritores do tópico, então moderno, cultura afro é que os mais influentes na colonização, devido a miscigenação, foram os descendentes africanos.

\begin{abstract}
"Entre 1502 e 1860, mais de 9 milhões e meio de africanos serão transportados para as Américas, e o Brasil figura como o maior importador de homens pretos. O século XVIII detém o recorde de importação: as Américas coloniais fizeram vir a elas 6 milhões e 200 mil escravos durante esse período (...)." (MATOSO, KÁTIA DE QUEIRÓS, Ser escravo no Brasil, São Paulo, Editora Brasiliense, 1990, pág. 19).
\end{abstract}

E através de um pensamento lógico podemos concluir isto: Um fazendeiro que vinha para a colonização em solo brasileiro teria de trazer, no mínimo, 2 escravizados para ajudar na lavoura, e, ao menos, 1 escravizada para ajudar a mulher em casa. Caso o casal tivesse filhos, o senhor teria que ter mais 2 escravizadas (levando em conta que seria 1 escravizada para cada filho), para ajudar com as crianças, que se fossem recém nascidas, para poder ajudar na amamentação, as mesmas escravizadas eram estupradas, como as vacas nas indústrias de laticínio, para produzir leite materno. Então acrescentamos mais 2 futuros escravizados, pois as negras estupradas teriam como consequência a gravidez. Então, para uma família de 4 europeus, teríamos $2+1+2+2=7$, seriam 7 escravizados. A literatura brasileira também teve seu papel muito influente na disseminação do racismo para seus brasileiros, os ensinando a reproduzirem o Preconceito Étnico-racial, e a pensarem em uma hierarquia racial dentro da sociedade.

\footnotetext{
"Ele propôs-lhe morarem juntos e ela concordou de braços abertos, feliz em meter-se de novo com um português, porque, como toda a cafuza, Bertoleza não queria sujeitar-se a negros e procurava instintivamente o homem numa raça superior à sua."(AZEVEDO, Aluísio de. O Cortiço. Editora: B. L. Garnier, 1890. Pg 3.)
}

Arriscamos também a enfatizar o fato da precariedade de escritores literários de descendência africana, na época, dando seus relatos, por mais que romantizados através da literatura, mas de cunho propriamente negro. O que levaria a pensar na literatura brasileira, da época, com um posicionamento totalmente branco, que levaria aquela antes citada manipulação do homem branco herói e evoluído. A indução ao preconceito foi, e ainda é, tão presente no Brasil. Fica evidente tal fato em uma pesquisa feita em 1976, a Pesquisa Nacional por Amostra de Domicílios (PNAD), pelo IBGE, onde foi perguntado 'qual a cor que as pessoas consideravam ter', Obtiveram exatamente 136 
respostas diferentes, e nenhuma delas foi negro ou afrodescendente. Dessas palavras, se destacam: 'Acastanhada, Enxofrada, Bugrezinha-escura, Meio-morena, Mestiça, Morena-bronzeada, Morena-clara, Mulatinha, Quase-negra, Queimada-de-praia, Tostada, Turva, Sapecada e Pouco-clara." Porém, segundo o IBGE, nos brasileiros somos compostos por 5 cores: A branca, parda, negra, indígena e amarela. O fato mais surpreendente, segundo uma edição de 1996 da revista VEJA, é que mesmo assim os brasileiros se consideram, em último lugar, um povo preconceituoso. Outra prova de que o brasileiro é induzido e reprodutor do preconceito, porém não reconhece, é em uma pesquisa feita na USP em 1988, que têm os dados a seguir:

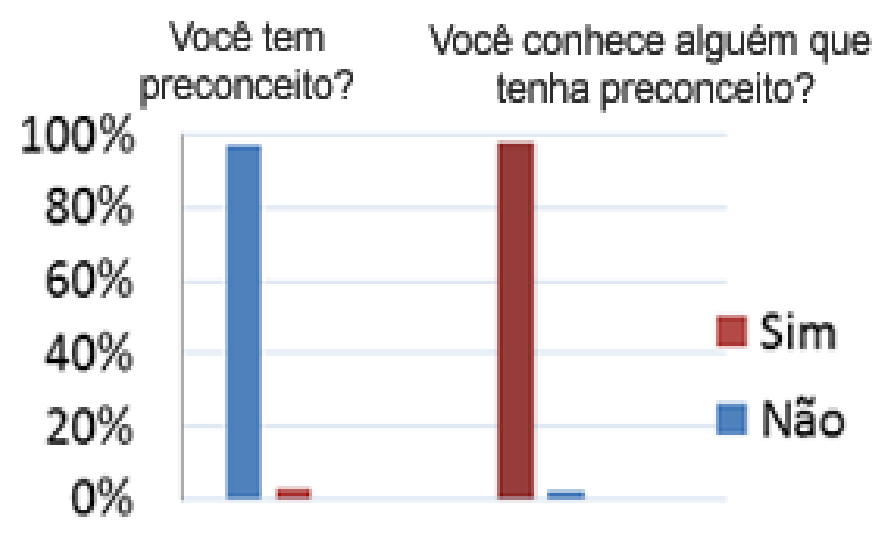

\section{QUESTÕES DE GÊNERO}

Para abordar a questão do gênero vamos primeiro trazer um histórico sobre o assunto a fim de demonstrar que se trata de uma construção social. Esta construção social vem desde a época da Europa Ocidental do Século XVI, onde os homens classificavam mulheres e crianças, com a justificativa que era de forma natural, como seres desprovidos de atributos e capacidades racionais. E isso refletiu em nós brasileiros na época da colonização. Antigamente, os filhos homens eram mandados para universidades estrangeiras, para tornarem-se cultos e nobres, enquanto as filhas se mantinham em casa aprendendo tarefas domésticas e, no máximo, algum conhecimento relacionado à Arte.

Vale mencionar a história de Francisca da Silva de Oliveira, mais conhecida como Chica da Silva. A ex-escravizada viveu no Brasil no século XVIII, durante o período colonial de mineração. O preconceito em relação a essa ex-escravizada já começara na forma com que sua história foi contada nas mídias. No seriado apresentado 
na Rede Globo, Chica é relatada como um objeto sexual, a 'mulata"' que disseminava a luxúria dentro do meio branco. Chica foi casada não oficialmente com João Fernandes, desembargador do Tribunal da Relação do Porto e juiz do Fisco das Minas Gerais, com quem teve 13 filhos. Então, pelo fato de Chica ter tido 13 gestações, é impossível que ela tenha tido tantas relações sexuais como é mostrado no seriado. Mas sabemos que já é de costume pela mídia brasileira, relatar mulheres negras como pedaços carnais, com o único fim de saciar o homem. Podemos ver isto nas novelas, nos seriados tais como Antônia (2006), Subúrbia (2012), Sexo e as Negas (2014), sempre com o mesmo estereótipo de erotização e submissão da mulher negra da favela, e nos desfiles carnavalescos, pois a mulher negra só aparece como musa e ainda assim, com apelo sexual, nas chamadas do Carnaval, no mesmo canal midiático que distorceu a história de Chica. Poucos são as histórias que retratam outras realidades.

Ainda há a visão de que a mulher tem que cuidar da casa e dos filhos, enquanto o homem estuda e trabalha. Tal idéia se reproduz em nossa educação. Tal como vemos em um exercício de um livro didático infantil, da Editora Positivo, onde relaciona figuras de um menino e de uma menina a afazeres que seriam, supostamente, designados para o gênero de cada um, entre algumas das opções temos "cuspir no chão" e "lavar louça", vejamos:

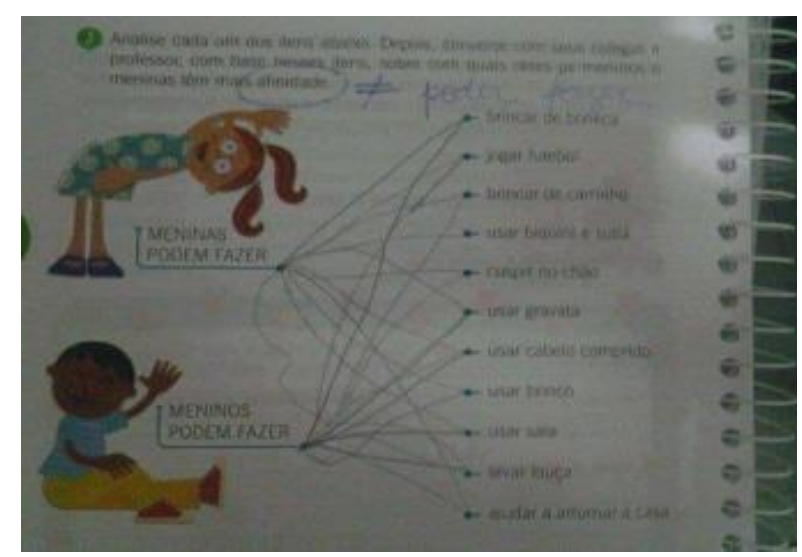

\section{ATIVIDADES PROPOSTAS}

No contexto do Acreditar, trazendo para o foco a questão da cultura negra, foi realizada uma oficina de danças urbanas reunindo as turmas pré-enem e pré-ifrs. Os educandos puderam conhecer e interagir um pouco mais com a cultura do hip hop, propiciando 
uma forma de abordagem valorizada dessa cultura e não pejorativa como geralmente ocorre nos materiais didáticos. Dessa maneira trabalha-se tanto o sentimento de pertencimento do educando além de propor a aproximação entre os cursos, educadores e educandos. Na mesma perspectiva, foi pensado no stencil, abordando a cultura africana e a mulher. Através do trabalho manual e do dialogo o educando passará pela teoria e pela pratica, de uma forma mais reflexiva e de livre expressão.

\section{PROPOSTAS NO CONTEXTO INDÍGENAS E QUILOMBOLAS}

Uma das maiores dificuldades desse contexto é a linguagem, visto que eles possuem língua própria, e a elaboração de dados estatísticos em seus respectivos cursos. As oficinas visam auxiliá-los nestas questões. Foram realizadas duas atividades, a de produção textual, atingindo os problemas de escrita, auxiliando na coesão e coerência de seus textos formulados e para a de estatística, pensando nos educadores. Dessa forma, visamos a permanência e ingresso dos membros dessa comunidade pertencente a uma camada popular na universidade, que antes não teriam esta oportunidade devido a nossa tão presente e ignorada ' exclusão social'. Nessas atividades não apenas o lúdico, mas também a criticidade são trabalhadas, pois no desenvolvimento das atividades há a reflexão a cerca dos temas propostos. Essas características apenas contribuem para um ambiente mais livre e sensível, facilitando assim o florescimento e o desenvolvimento do pensamento crítico.

\section{CONCLUSÃO}

Concluímos, acerca dos argumentos utilizados ao decorrer deste trabalho, que as cotas são de suma importância. A prática dos preconceitos perpetuam em nossa realidade atual, a partir de acontecimentos e construções sociais históricas, reproduzidas nos veículos da educação, aplicados nas instituições de ensino, diminuindo as oportunidades de acesso a educação, o que é na realidade, um direito de todos.

\section{REFERÊNCIAS}

AZEVEDO, Aluísio de. O Cortiço. Editora: B. L. Garnier, 1890. 
FALAVINHA, Karina; CONCEIÇÃO, Sarasvati Y.Z. O lugar da infância e da mulher em livros didáticos e textos jornalísticos: um olhar a partir da historia. Seminário de Educação. Paraná, 2012

MATOSO, KÁTIA DE QUEIRÓS, Ser escravo no Brasil, São Paulo, Editora Brasiliense, 1990

ROMERO, Silvio. Complexo do Zé Carioca, 1953 in: SCHWARCZ, L.K.M. Negras Imagens, 1993.

RAMOS, Fábio Pestana \& MORAIS, Marcus Vinicius. Eles formaram o Brasil. São Paulo: Contexto, 2010. 